\title{
Determinants of Subjective Well-Being and Invariance Measurement: Evidence from German and Ghanaian Data
}

\author{
Muhammad Ba \\ Economics, and Management Department, Gaston Berger University, Saint-Louis, Senegal \\ Email: ba.muhammad@ugb.edu.sn
}

How to cite this paper: Ba, M. (2020). Determinants of Subjective Well-Being and Invariance Measurement: Evidence from German and Ghanaian Data. Open Journal of Social Sciences, 8, 61-85. https://doi.org/10.4236/jss.2020.88006

Received: July 7, 2020

Accepted: August 11, 2020

Published: August 14, 2020

Copyright $\odot 2020$ by author(s) and Scientific Research Publishing Inc. This work is licensed under the Creative Commons Attribution International License (CC BY 4.0).

http://creativecommons.org/licenses/by/4.0/

\section{(c) (i) Open Access}

\begin{abstract}
This paper aims to test the invariance measures of subjective well-being and some of its determinants using Ghanaian and German data from the WVS (World Value Survey). From the WVS wave- 6 data, the following dimensions are selected: religion, social capital, social trust, fear feeling or worry, political activities, personalities, security, economic conditions, and subjective well-being. To test the different types of invariance (configural invariance and metric invariance), MGCFA (Multi-group Confirmatory Factor Analysis) was used. The first result of our modeling was that all dimensions significantly determine subjective well-being in the local model with the German data. In contrast to the Ghanaian data, only the dimensions of political activity and the fear feeling or worries turn out not to be significant in explaining subjective well-being. Second, the configural invariance test revealed that social capital, religion, social trust, fear feelings or worries, and economic conditions are non-equivalent between the two countries. Security, political activities, and subjective well-being satisfy the partial invariance measurement. Only personality traits are fully invariant across the two countries. As a result, a comparison of the determinants of well-being across the two countries is only possible for personality traits (full invariance measurement) and security (partial invariance measurement).
\end{abstract}

\section{Keywords}

Subjective Wellbeing, Germany, Ghana, Invariance Measurement, MGCFA

\section{Introduction}

Subjective well-being has, in recent years, gained considerable interest in economic and psychological research, in particular. In economics, following the 
work of Easterlin (1974), many empirical studies have tried to link economic growth and happiness. Also, using econometric models, much empirical research estimated the effects of socio-economic factors on happiness. This literature shows that subjective well-being varies with income, age, and marital status, but also according to the cultural context. Moreover, personal perceptions such as happiness or subjective well-being depend on several sociological factors. They may have different meanings in different societies. For example, the linguist Anna Wierzbicka (2004) has shown that while happiness in English refers to a minor positive feeling; in French, German or Russian, it is close to a major and rare positive event. Similarly, Tsai et al. (2007) compares happiness in Christian and Buddhist texts and find that in the former it is represented by a high emotion; whereas in the latter, it is thought of as a low positive emotion. Given this difference in the conception and measurement of subjective well-being across different cultures, a comparative analysis should first check the equivalence measurement (or the measure of invariance), to avoid biased, erroneous or invalid results. Measurement equivalence is a criterion that describes the property of a measuring instrument to evaluate the same concept in a similar way across different groups (Chen, 2008).

Measurement equivalence is then a precondition for comparing measurements across groups that differ by culture, gender, or other socio-economic factors. Several studies have empirically tested the equivalence of different measures across different societies. Thanks to the development of international databases (Afrobarometer, Eurobarometer, European Social Survey (ESS), World Value Survey (WVS), etc.) and the use of quantitative techniques such as Multigroup Confirmatory Factor Analysis (MGCFA), most of these studies have found the non-invariance in many concepts across different cultures such as religious commitment (Billiet, 2013); relationship to ecology (Boeve-de Pauw et al., 2014); political orientation (Piurko et al., 2011); democratic values (Ariely \& Davidov, 2011); constructivist patriotism and nationalism (Davidov, 2009); and so on.

Concerning subjective well-being, despite a large amount of comparative work between countries, the issue of testing measurement equivalence is not very present. However, some work has tested measurement equivalence across cultures using the Satisfaction With Life Scale (SWLS) of Diener et al. (1985) (Diener et al., 2013; Emerson et al., 2017; Zanon et al., 2014).

This paper aims to contribute to the empirical literature on the subjective well-being measurement equivalence test. The research question is: Are measures of subjective well-being and its determinants non-equivalent across European and African cultures? Thus, we will compare subjective well-being measurement and its determinants (religion, personality, political activities, security, worries, etc.) between two societies belonging to very opposite cultural areas (Welzel, 2013): Germany and Ghana. The indicators and dimensions are selected from the WVS data.

The choice of Germany and Ghana comes from an examination of the cultural 
map by Inglehart \& Welzel (2005) where the countries are arranged in a matrix in which they are identified along two axes: traditional and secular values, on the one hand, and values of survival and self-expression, on the other. The authors thus identify nine different cultural regions. These are African-Islamic; Latin America; English Speaking; South Asia; Orthodox (Catholic); Catholic European; Baltic; Confucian, and Protestant Europe. The comparison in this paper focuses on two opposite cultural regions: the cultural area of European countries with Protestant traditions and that of African and Islamic countries. It is from these two groups that we have chosen the countries that pose the least constraints in terms of data availability in the selected variables. From an exploratory perspective, the comparison in this study will focus on Ghana and Germany, which after the elimination of missing data provide a sample whose difference is not so great.

Compared to the existing literature, to our knowledge, this paper is a contribution to the literature on several aspects. First, it seeks in an exploratory perspective to compare subjective well-being and its determinants between African and European cultures (Germany and Ghana). Second, this study uses the permutation method of the PLSPM-SEM (Partial least square path modeling-Structural Equation Modeling (SEM)) approach to test invariance, which would be a first in the empirical literature on subjective well-being.

The rest of the paper is structured as follows. In the second section, the theoretical background of equivalence measurement is presented. A third section explains the data sources, the methodology used, and the specification of the model. A fourth section is devoted to the presentation of the results. A fifth section concludes and discusses the results.

\section{Theoretical Background}

\subsection{Source of Equivalence Bias}

Before presenting the methods for detecting measurement equivalence, let us ask the question: what is the source of measurement non-invariance? According to Van de Vijver (1998), there are three types of biases that affect equivalence: construct bias, method bias, and item bias.

The first type of bias: the construct bias is the most crucial, it denotes that the theoretical concept has a different meaning across different groups (Davidov et al., 2014). The problem that is raised with such a bias comes back to that of the comparison of concepts as raised by Triandis (1972) in sociology by distinguishing: the emic concept, and universal, or etic concept. The emic concept has a meaning that is specific to a culture, unlike the universal or etic concept.

Method bias, the second type of bias, relates to the method used in sampling techniques, the treatment of non-response, and the procedures for administering questionnaires. Besides, this type of bias can lead to differences in scores between groups, which refer to a social desirability bias (Johnson \& Van de Vijver, 
2003).

Finally, item bias refers to anomalies observed in the translation of items (Harkness et al., 2010). It may also be due to the inclusion of a term that has a different interpretation from one society to another. Davidov et al. (2014) give an example of environmental protection, which may have different understandings among socio-cultural groups.

\subsection{Methods for Testing Measurement Invariance}

To correct these biases, it is possible to act a priori in the formulation of questionnaires by taking into account the translation question or to conduct cognitive interviews (Fitzgerald et al., 2011; Willis, 2004). However, according to several authors, no measure, a priori, can guarantee the comparability of a concept between two or more groups (Byrne et al., 2009; Chen, 2008; Davidov et al., 2011). It is therefore important to estimate the measure of invariance.

In this sense, there are several techniques for estimating the measure equivalence. Davidov et al., (2014) list the following techniques: Exploratory factor analysis (Meredith, 1964); MGCFA (Multi-Group Confirmatory Factorial Analysis) (Jöreskog, 1971); multidimensional scaling (Braun \& Scott, 1998); Item Response Theory (IRT) (Raju et al., 2002); Latent Class Analysis (LCA) (Kankaraš et al., 2010).

The MGCFA technique is the most popular of all and belongs to the family of latent classes. It detects invariance at three levels: configural invariance; metric invariance and scale invariance. Configural invariance assumes that a construct is measured in a similar way across different groups. In other words, the general structure of factors must be the same across different sub-samples. Metric invariance indicates that the correlation of measures or predictors can be compared across different groups. Finally, scale invariance determines whether the item intercepts are equal across sub-samples. Agreeing with Davidov et al. (2014), scale invariance is rarely found in cross-cultural comparative studies. The MGCFA is used in the context of modeling by SEMs that estimate two models: the measurement or outer model and the structural or inner model. With the measurement model, invariance testing indicates whether the items used mean the same thing to respondents from different groups (Chin et al., 2016). Concerning, structural model, the MGCFA indicates whether the structural path is equivalent across the group (Chin et al., 2016). However, the MGCFA does not provide information to determine whether the observed differences are true differences or just a psychometric difference in item responses. In SEM, two estimation techniques are generally used: the covariance-based technique (CBSEM) or LISREL and the variance-based technique or SEM-PLS. In the literature on the equivalence measurement, the use of the MGCFA is based more on a CBSEM (Byrne, 2010; Doll et al., 2004; Malhotra \& Sharma, 2008). This approach uses the differences between the group models chi-square $\left(\chi^{2}\right)$ to test invariance. Furthermore, as Chin et al. (2016) note, this approach has the disadvantage of 
imposing a series of constraints on all parameters (factors, variance, and structural coefficients) to test invariance. This multitude of compulsion can lead to concealing non-invariance at much lower levels of analysis (Chin et al., 2016: p. 271). Also, this approach is very constraining in terms of the nature of the data and sample size.

With this in mind, alternative approaches are increasingly being used to test invariance in MGCFAs. Among these techniques is the PLS permutation approach proposed by Chin et al. (2016). This approach is part of the other technique for estimating SEM: PLS-PM or the variance-based approach. It is a less constraining technique in terms of data type and sample size. Unlike the CBSEM-based MGCFA, this approach allows testing the invariance at several levels of the analysis with the permutation test. This method is a non-parametric resampling procedure developed by Chin \& Dibbern (2010). It is based on a repetitive random permutation procedure that ultimately seeks to test whether the difference between the structural coefficients is large enough to reject the null hypothesis that postulates an identity between the two groups. In this paper, we will use the latter technique to test invariance in subjective well-being configuration and its determinants.

\subsection{Literature Review}

Equivalence is then a necessary precondition for the comparison of measures between groups that differ by culture, gender, or other socio-economic factors. Several studies have empirically tested the equivalence of different measures. Most have concluded that the concepts are not comparable across countries. For example, With the WVS data, Ariely \& Davidov (2011) found that the scales commonly used to measure attitudes across democratic societies do not have the same meaning across countries. Piurko et al. (2011) showed with the SSE data that questions on policy orientations (right and left) have a different meaning between Eastern and Western European countries. They find that a common question may refer to different ideological orientations depending on whether the respondent is from a liberal (Sweden), traditional (Greece), or post-communist (Czech Republic) country. Boeve-de Pauw et al., (2014) found by observing a non-invariance that the different attitudes of Belgian children towards the ecological issue would be linked to the gender difference which would lead to a lack of comparability between the two sexes. Also, Alemán \& Woods (2016) tested the invariance using WVS data over the period 1981 to 2014 and found that most of the values defined in this database are not comparable between countries, except for a few European postmaterialist countries. The conclusions of these two authors will also be reinforced by Sokolov, (2018) who observed non-equivalence in the Inglehart \& Welzel (2005) emancipatory value index measurement model. With the MGCFA technique, he found that this index is not invariant across the ten different cultural zones defined by Inglehart \& Welzel (2005), except for the choice dimension which only satisfied this criterion after estimation via a Baye- 
sian approach.

On the opposite, some studies are not as categorical about the existence of invariance of concepts across different groups. Thus, Davidov, (2009) demonstrates that values such as constructivist patriotism, nationalism, among others, are comparable across different countries in the International Social Survey Program (ISSP) database. Nover (2012) finding partial weak measurement invariance in the Questionnaire-Social Support (F-SozU-22; Fydrich et al., 2009) for pupils in Germany, Luxembourg, and Spain. Beside he detected an invariance of social support among the German and Luxembourgian pupils. However, between the German and Spanish pupils, strong measurement invariance could not be established in samples. Freitag \& Bauer, (2013) again using WVS data, found an invariance in the measurement of social trust between German-, Frenchand Italian-speaking countries and part of Switzerland. Similarly, Poznyak et al., (2014) find that social trust has invariant over time using American data (American National Election Studies) from 1964 to 2008.

For comparisons of well-being, the literature has placed more emphasis on measuring life satisfaction. Satisfaction with Life Scale (SWLS; Diener et al., 1985) is using to measure life satisfaction. Therefore, Tucker et al. (2006) using a small student and community samples in the United States and Russia, found strong measurement invariance in student samples but only weak measurement invariance in community samples. The SWLS scores were not comparable across the US and Russian community-based groups. Oishi (2006) conducted a study with American and Chinese students, applying an item response theory analysis, which revealed that Items 4 and 5 assessing "one's satisfaction with past accomplishments" showed an item bias across the two cultural groups. In another study, Zanon et al. (2014) examined measurement invariance between students from the United States and Brazil using MGCFA and also found that Items 4 and 5 of the SWLS were noninvariant. Tomás et al. (2015) examined the configural, metric, and scalar invariance of the Portuguese version of the SWLS across age and gender with a sample of 5630 Angolans. The results showed that the scalar invariance of the SWLS held across gender and age. With three test measurement invariances, i.e. 1) multigroup confirmatory factor analysis (MGCFA), 2) multilevel confirmatory factor analysis (ML-CFA), and 3) alignment optimization methods, Jang et al. (2017) demonstrated that configural and metric invariances of SWLS held across 26 countries, whereas scalar invariance did not. Also, they identified, with partial invariance, only two of five items were invariant across 26 countries. Jovanović \& Brdar (2018) evaluated the measurement invariance of the SWLS across five European countries: Austria, Bosnia and Herzegovina, Croatia, Montenegro, and Serbia. With a sample of 1162 students, their finding supported measurement invariance across five countries.

Other studies have examined invariance across different groups with alternative wellbeing measurement. Żemojtel-Piotrowska et al., (2017) examined the measurement invariance of the 8-item Personal Well-Being Index (PWI-8) with 
a sample of students from 26 countries. Using a conventional approach and the alignment procedure, their results showed partial configural and metric invariance, as well as partial scalar invariance between samples. Their results then suggest the use of PWI- 8 to examine correlates of life satisfaction in all included countries, but not for cross-country comparisons. In a sample of German, Chinese and Russian students, Bieda et al. (2017) found partial invariance for SWLS and other constructs such as social support, optimism, and resilience. On the other hand, invariance is not observed for the Subjective Happiness Scale (SHS) which describes the cognitive aspect of well-being. Finally, one of the latest studies to our knowledge is that of Tian et al., (2020). They tested measurement invariance configural of Brief Adolescents' Subjective Well-being in School Scale (BASWBSS) across three school levels (i.e. elementary, middle, and high school) with Chinese children and adolescents. Their results with MGCFA showed three non-invariant items (i.e. Items 4, 6, and 7 from the School Satisfaction subscale) and concluded for partial scalar invariance across school levels. They subsequently found, by comparing the latent mean difference, that elementary students' satisfaction was higher than middle and high students.

\section{Data and Measures}

\subsection{Source of Data}

This article uses WVS data for two countries for exploratory purposes: Germany and Ghana. The WVS is a database that has been documented since 1980 and collects perception data on several dimensions of life (cultural values, attitudes and beliefs towards gender, family, and religion; attitudes and experience of poverty; education, health, and security; social tolerance and trust; attitudes towards multilateral institutions; cultural differences and similarities between regions, and societies). Today this database covers more than 60 countries with 6 rounds. The seventh (WVS-7) is in progress and should be published during 2020 and will lead to a coverage of 80 countries. WVS- 6 surveys covered all residents (not just citizens) in a country at the age of 18 years older and older. A full probability sample of the population aged 18 and over was used as the sampling process in this survey. In some cases, the application of a nationally representative random sample based on a stratified, multi-stage territorial selection has been allowed. Other sample design models were also possible depending on the concrete conditions of the country. The main objective was to achieve the samples in each country are representative and reflect the distribution observed in the country's population according to gender, age groups, urban/rural population, etc. Thus, the minimum acceptable sample size, in the vast majority of countries, in national data sets is 1200 . However, where the country has a population of less than 2 million, a sample size of 1000 is considered acceptable; but this sample size should be at least 1500 when the country's population is large. The sample for Ghana and Germany is 1501 and 1529 respectively. At this level, the sample size is representative of the population of each of these two countries. 
Table 1 summarizes some information on the socio-demographic description of the two populations.

\subsection{Definition of Variables}

In this paper, nine dimensions are selected and measured with items from the WVS. These dimensions are considered as latent variables in the model that will be specified in 3.3. From the literature, we have chosen the following dimensions: religion, social capital, social trust, political activities, security, feelings of fear or worry, personality traits, and economic status. Thus, each variable is defined by at least three indicators (see Table 2). In Appendix, a more complete table is given with the measurement scales for each indicator (see Table A1 in Appendix).

Table 1. Distribution of the sample from the two countries according to some socio-demographic variables.

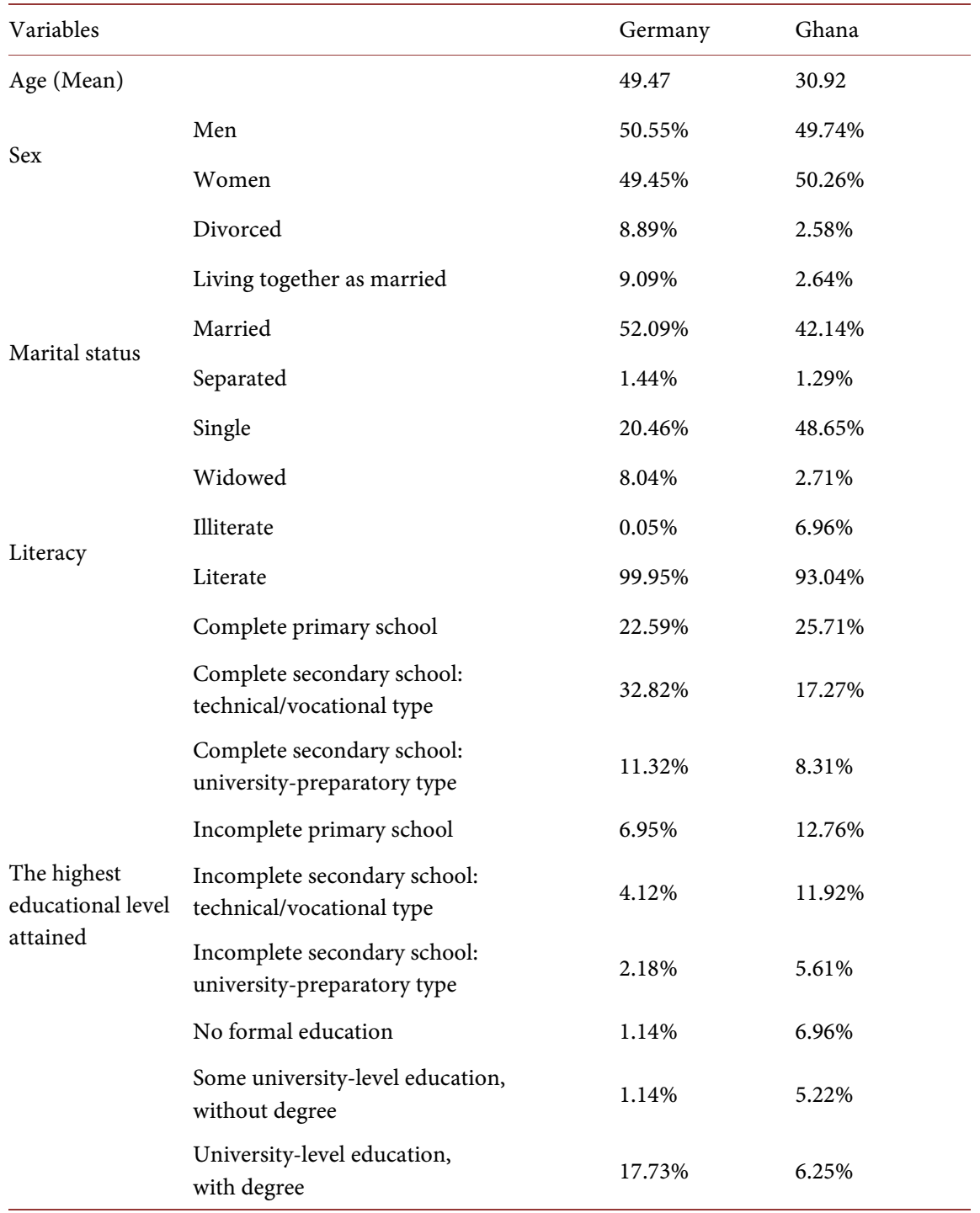

Source: Author from WVS-6 data. 
Table 2. Dimensions and indicators.

\begin{tabular}{|c|c|c|}
\hline Dimension & Indicator & Definition in WVS \\
\hline \multirow{3}{*}{ Social Capital } & Socap1 & $\begin{array}{l}\text { Active/Inactive membership: Sport or recreational } \\
\text { organization }\end{array}$ \\
\hline & Socap2 & Important in life: friends \\
\hline & Socap3 & Important in life: times leasures \\
\hline \multirow{5}{*}{ Religions } & Rel1 & How often to pray \\
\hline & Rel2 & How often do you attend religious services \\
\hline & Rel3 & Important in life: religion \\
\hline & Rel4 & How important is God in your life \\
\hline & Rel5 & $\begin{array}{l}\text { Active/Inactive membership: Church or Religious } \\
\text { organization }\end{array}$ \\
\hline \multirow{3}{*}{ Social Trust } & Trust1 & How much you trust: Your family \\
\hline & Trust2 & How much you trust: Your neighborhood \\
\hline & Trust3 & How much you trust: people you know personally \\
\hline \multirow{4}{*}{ Personality } & Perso1 & $\begin{array}{l}\text { Schwartz: It is important to this person to think up new ideas } \\
\text { and be creative; }\end{array}$ \\
\hline & Perso2 & $\begin{array}{l}\text { Schwartz: It is important to this person to be rich; to have a lot } \\
\text { of money and }\end{array}$ \\
\hline & Perso3 & $\begin{array}{l}\text { Schwartz: Adventure and taking risks are important to this } \\
\text { person; to have an ex }\end{array}$ \\
\hline & Perso4 & $\begin{array}{l}\text { Schwartz: Being very successful is important to this person; } \\
\text { to have people recognition }\end{array}$ \\
\hline \multirow{4}{*}{$\begin{array}{l}\text { Political } \\
\text { activities }\end{array}$} & Actpol & Political action: Signing a petition \\
\hline & Actpo2 & Political action: Joining boycotts \\
\hline & Actpo3 & Political action: Joining stricks \\
\hline & Actpo4 & Political action: attending peaceful demonstration \\
\hline \multirow{3}{*}{ Fear } & Fear1 & Worries: A war involving my country \\
\hline & Fear2 & Worries: A terrorist attack \\
\hline & Fear3 & Worries: A civil war \\
\hline \multirow{3}{*}{ Security } & Secul & Respondent was victim of a crime during the past year \\
\hline & Secu2 & Respondent's family was victim of a crime during last year \\
\hline & Secu3 & $\begin{array}{l}\text { In the last } 12 \text { month, how often have you or your family: Felt } \\
\text { unsafe from crime }\end{array}$ \\
\hline \multirow{3}{*}{$\begin{array}{l}\text { Economic } \\
\text { conditions }\end{array}$} & Ecosit1 & Scale of incomes \\
\hline & Ecosit2 & Social class (subjective) \\
\hline & Ecosit3 & Satisfaction with financial situation \\
\hline \multirow{2}{*}{$\begin{array}{l}\text { Subjective } \\
\text { wellbeing }\end{array}$} & Swb1 & Satisfaction with your life \\
\hline & Swb2 & Happiness feeling (happiness scale) \\
\hline
\end{tabular}

Source: Author. 
Social capital refers to the extent of an individual's social network. More specifically, it refers to social ties, which measured by Active/Inactive membership: Sport or recreational organization, the importance of friends in life, and the importance of leisure time in life. Social capital is supposed to have a direct effect on subjective well-being, as illustrated by Helliwell \& Putnam (2004) who showed that good relationships with family, friends, neighbours or partners are more important to people's happiness than celebrity or money.

Religion is a dimension that is defined in this research by 5 items. These items refer to religious commitment (Active/Inactive membership: Church or Religious organization), religiosity (How often do you attend religious services, How often to pray, and Important in life: religion) and faith (How important is God in your life). Religion has a direct effect on subjective well-being. For example, as suggested by the results of Lim \& Putnam, (2010) the religious people are more satisfied with their lives.

Social trust is a dimension whose items relate to trust in neighbours, family members and people one knows. Social trust is a dimension whose items relate to trust in neighbours, family members, and people one knows. The effect of social trust on well-being can be both positive and negative. In this study, it's assumed that this dimension has a positive and strong effect on subjective well-being (Churchill \& Mishra, 2017).

The personality dimension refers to the personality traits that are characteristics of our motivational system and that determine what we do in the absence of strong influence. Personality is measured in this study by 4 personality traits defined by Schwartz which are related to the sense of imagination and creativity, the desire for recognition, the love of adventure and risk, and the importance given to money and wealth. Personality traits are supposed to have a positive effect on subjective well-being, as the Ha \& Kim (2013) have shown in the south Korean context by finding that personality trait (measured by the Five-factor model) - particularly, Emotional Stability and Extraversion-are positively associated with happiness and life satisfaction, after controlling for other covariates.

The political activities dimension refers to the indicators chosen in the WVS that provide information on the individual's political actions in terms of the signed petition, joining boycotts, joining stricks, and attending a peaceful demonstration. Political activities are assumed to have a positive effect on subjective well-being. With ESS data Šarkute, (2017) showed that all subjective wellbeing indicators are correlated with at least two indicators of political activism in European countries.

The fear feeling is a dimension that in WVS-6 groups together all the indicators that refer to worry. Among these indicators, we have selected the worry of seeing one's country engage in war, the worry of a terrorist attack, and the worry of a civil war. Like other negative emotions, fear feeling or worry has a direct effect on subjective well-being, although there are no studies in the literature that test this relationship. 
The sense of safety is given by indicators related to the crime experienced by the individual in the past or by one of his or her family members, but also by the frequency of a perception of being unsafe. It is clear that a sense of insecurity harms the quality of life and subjective well-being (Stiglitz et al., 2009). In this sense, security is assumed to have a direct effect on subjective well-being in this paper.

Economic conditions define an individual's financial situation. It is measured by the individual's perception of his or her financial situation, the scale of income, and the social class to which he or she feels he or she belongs. Economic conditions, particularly income, have a positive effect on subjective well-being (Diener, 1984; Easterlin, 2001; Stevenson \& Wolfers, 2013). In this paper, too, economic conditions are assumed to have a direct effect on subjective well-being.

Subjective well-being is constructed based on these components: life satisfaction and the feeling of happiness (Veenhoven, 2010). This is the dependent variable of our model and all variables have been shown in the literature to be determinants of subjective well-being (Diener et al., 2003; Helliwell, 2005, 2008; Helliwell \& Putnam, 2004; Stanzani, 2015).

\subsection{Model Specification}

This paper adopts a PLS-PM model of MES. These models are composed of two parts: an outer model and an inner model. In the latter, we will test the relationship between the latent variables that are represented in this paper by subjective well-being and its determinants.

The inner model will highlight the effects of the eight selected dimensions on subjective well-being. It can be formally written as follows:

$$
\xi_{\text {swb }}=\beta_{0}+\sum_{i} \beta_{i} \xi_{i}+\mu
$$

with $\xi_{s w b}$, the endogenous latent variable, i.e. subjective well-being, $\xi_{i}, i$ exogenous or model-independent latent variables, i.e. the eight (8) determinants selected. $\beta_{0}$ represents the intercept of the model. $\beta_{i}$ is a structural path associated with the relationship between the endogenous latent variable and the exogenous latent variables. $\mu$ represents the error term or disturbance.

Each latent variable is associated with a block of manifest variables. The set of relationships between latent variables and manifest variables forms the external model or measurement model. In our model, the manifest variables are assumed to reflect the latent variables. The external model is written as follows:

$$
x_{h}=\pi_{h 0}+\pi_{h} \xi+\varepsilon_{h}
$$

where $x_{h}$ is a manifest variables vector for the latent variables $\xi, \pi_{h}$ is a loading associated with the manifest variables $x_{h}$, and $\varepsilon_{h}$ is a measurement error term for manifest variables.

The error terms, in (1) and (2), should have a null mean and should be uncorrelated with the latent variables $\xi$ (Tenenhaus et al., 2005).

The figure shows the specified model schematically. The different dimensions 
or latent variables are in elliptical figures. The manifest or indicator variables from the WVS- 6 database are shown in rectangular figures.

The results of the model will be analyzed according to the quality of the global model, the outer model, and the inner model.

The global model is analyzed in terms of goodness of fit. For this, it is recommended that absolute GoF be greater than 0.35 (Wetzels et al., 2009). It is also possible to observe also the relative GoF, which according to (Vinzi \& Russolillo, 2010) must be greater than 0.90 . The relative GoF can also be observed in addition to the absolute GoF.

The inner model validity is more concerned with the observation of structural paths that measure the effect of latent constructs on each other. Also, it is recommended to analyze the predictive quality of the model. Redundancy is the statistic that makes it possible to assess this quality. It determines the ability of the independent latent variables to predict the endogenous latent variable.

The outer model results are analyzed in the PLS-PM approach in terms of internal consistency, reliability indicators, and convergent and divergent validity. The internal consistency reflects the requirement for the homogeneity of the constructions. To this end, the $\rho$ Dillon Goldstein must be greater than 0.7. (Chin, 1998) The threshold of 0.6 is also allowed by Bagozzi et al. (1998). The indicator's reliability requires that they be well explained by their latent variable. For this, they must have a communality that is equal to or greater than 0.5 or a loading equal to or greater than 07 (Chin, 1998). Furthermore, Barclay et al., (1995) considered that the threshold of 0.5 for loading may be acceptable for indicators reliability. Convergent validity refers to the ability of indicators to converge in the measurement of their latent variable compared to indicators measuring different constructs. The criterion of validity is based on Average Variance Extracted (AVE) which must be greater than or equal to 0.5 according to Fornell \& Larcker (1981). Finally, the last criterion is external validity, which measures the fact that a manifest variable reflects only its latent variable. For this criterion, the AVE of each latent variable should be greater than the latent variable highest squared correlation with any other latent variable (Fornell \& Larcker, 1981).

\section{Results}

MGCFA is based first on estimating the general model with data from the different groups. This results in local models that are in this paper the model with the Ghanaian and German data. The model in Figure 1 is then estimated for Ghana and Germany respectively. The comparison of the different parameters of the model gives an estimate of the measurement invariance between the two countries. Therefore, in this paper, the results of each local model are presented before analyzing the measurement invariance which is a comparison of the difference in the parameters of the two models. Besides, the descriptive results of the overall model are given in the appendix (see Table A2 in Appendix). 


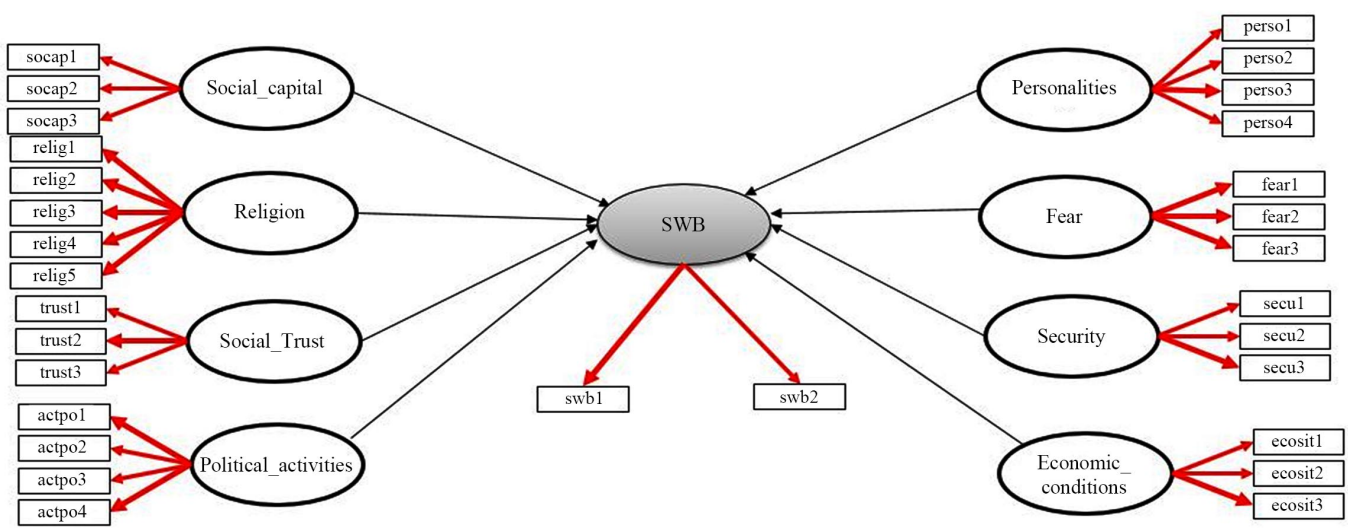

Figure 1. Graphical representation of the model to be estimated. Source: Authors, from XLSTAT-PLSPM (2014).

\subsection{The Local Ghanaian Model}

The global model for Ghana has an absolute GoF of 0.35 . This is a fair value compared to the threshold defined by Wetzels et al. (2009), while the relative GoF is below the 0.9 thresholds defined by Vinzi \& Russolillo (2010). Based on these two indicators, it can be concluded that the model adjusts moderately to the Ghanaian data (see Table 3).

Concerning the outer model, the internal consistency is verified for all latent variables that have Dillon Goldstein $\rho$ between 0.689 and 0.9727 . For the reliability of the indicators, only the indicators of the constructs of "subjective well-being" and "economic conditions" have loadings or communalities above the different thresholds. The convergent validity of the constructs is observed for the following dimensions: social trust, political activities, fear feeling, economic conditions, and subjective well-being (see Table 4).

Analysis of the inner model shows that all dimensions have a positive and significant effect on subjective well-being, except for political activities and the fear feeling. The most important determinant is related to economic conditions and social capital (see Table 5).

\subsection{The Local German Model}

The local model for Germany has an absolute and relative GoF that is above the different thresholds used to judge the fit quality of the model. Thus, the model appears to fit well with the German data.

The outer model fully satisfies the criterion of internal consistency with Dillon Goldstein $\rho$ all of which are above 0.7 . Concerning the reliability of the indicators, the results meet the reliability criterion better than the outer local Ghanaian model. There are only a few indicators in the "personalities" block (perso2 and perso3) and the "security feeling" block (secu1) that have loadings below 0.6. Convergent validity is observed for the following dimensions: religion; political activities; subjective well-being; economic conditions and fear feeling (see Table $4)$. 
Table 3. The global model fit quality for the two countries.

\begin{tabular}{ccccccc}
\hline & \multicolumn{3}{c}{ Ghana } & \multicolumn{3}{c}{ Germany } \\
\cline { 2 - 7 } & GoF & Lower limit (95\%) & Upper limit (95\%) & GoF & Lower limit (95\%) & Upper limit (95\%) \\
\hline Absolu & 0.35 & 0.28 & 0.31 & 0.38 & 0.38 & 0.39 \\
Relatif & 0.87 & 0.78 & 0.84 & 0.9 & 0.89 & 0.92 \\
Outer Model & 0.96 & 0.86 & 0.92 & 0.98 & 0.98 & 0.99 \\
Inner Model & 0.90 & 0.90 & 0.91 & 0.91 & 0.91 & 0.93 \\
\hline
\end{tabular}

Source: computations performed by the author using the XLSTAT-PLSPM software.

Table 4. Outer model results for the two countries.

\begin{tabular}{|c|c|c|c|c|c|c|c|c|c|c|c|}
\hline \multirow{2}{*}{$\begin{array}{c}\text { Latent } \\
\text { Variables }\end{array}$} & \multirow{2}{*}{$\begin{array}{l}\text { Manifest } \\
\text { Variables }\end{array}$} & \multicolumn{5}{|c|}{ Ghana } & \multicolumn{5}{|c|}{ Germany } \\
\hline & & $\begin{array}{c}\text { Cronbach } \\
a\end{array}$ & D.G.Rho & Loadings & Communalities & AVE & $\begin{array}{c}\text { Cronbach } \\
a\end{array}$ & D.G.Rho & Loadings & Communalities & AVE \\
\hline \multirow{3}{*}{ Social_capital } & socap1 & 0.3262 & 0.6895 & 0.4444 & 0.1975 & 0.4108 & 0.3930 & 0.7078 & 0.6342 & 0.4022 & 0.4519 \\
\hline & socap2 & & & 0.5233 & 0.2738 & & & & 0.7164 & 0.5132 & \\
\hline & socap3 & & & 0.8725 & 0.7612 & & & & 0.6635 & 0.4402 & \\
\hline \multirow{5}{*}{ Religion } & relig1 & 0.5176 & 0.7140 & 0.4101 & 0.1682 & 0.2840 & 0.9080 & 0.9319 & 0.8286 & 0.6865 & 0.7170 \\
\hline & relig2 & & & 0.3165 & 0.1002 & & & & 0.9156 & 0.8383 & \\
\hline & relig3 & & & 0.7442 & 0.5538 & & & & 0.8703 & 0.7575 & \\
\hline & relig4 & & & 0.6538 & 0.4274 & & & & 0.8404 & 0.7063 & \\
\hline & relig5 & & & 0.4126 & 0.1702 & & & & 0.7723 & 0.5965 & \\
\hline \multirow{3}{*}{ Social_Trust } & trust1 & 0.7005 & 0.8340 & 0.6464 & 0.4179 & 0.6103 & 0.4876 & 0.7450 & 0.7355 & 0.5410 & 0.4877 \\
\hline & trust2 & & & 0.7759 & 0.6021 & & & & 0.7441 & 0.5537 & \\
\hline & trust3 & & & 0.9005 & 0.8109 & & & & 0.6070 & 0.3684 & \\
\hline \multirow{4}{*}{$\begin{array}{l}\text { Political__ } \\
\text { activities }\end{array}$} & actpol & 0.7940 & 0.8663 & 0.6108 & 0.3730 & 0.5631 & 0.7529 & 0.8438 & 0.8406 & 0.7067 & 0.5654 \\
\hline & actpo2 & & & 0.7204 & 0.5189 & & & & 0.6538 & 0.4275 & \\
\hline & actpo3 & & & 0.7181 & 0.5157 & & & & 0.7020 & 0.4928 & \\
\hline & actpo4 & & & 0.9190 & 0.8446 & & & & 0.7968 & 0.6348 & \\
\hline \multirow{2}{*}{ SWB } & swb1 & 0.5961 & 0.8320 & 0.8774 & 0.7698 & 0.7105 & 0.7579 & 0.8920 & 0.9214 & 0.8489 & 0.8031 \\
\hline & swb2 & & & 0.8069 & 0.6512 & & & & 0.8702 & 0.7572 & \\
\hline \multirow{4}{*}{ Personality } & persol & 0.5152 & 0.7333 & 0.6388 & 0.4081 & 0.4059 & 0.5932 & 0.7662 & 0.8730 & 0.7621 & 0.4028 \\
\hline & perso2 & & & 0.6746 & 0.4551 & & & & 0.4368 & 0.1908 & \\
\hline & perso3 & & & 0.5182 & 0.2686 & & & & 0.5380 & 0.2895 & \\
\hline & perso 4 & & & 0.7014 & 0.4919 & & & & 0.6072 & 0.3687 & \\
\hline \multirow{3}{*}{ Fear } & fear1 & 0.9579 & 0.9727 & 0.8603 & 0.7401 & 0.6562 & 0.8402 & 0.9038 & 0.8608 & 0.7410 & 0.7559 \\
\hline & fear2 & & & 0.8922 & 0.7960 & & & & 0.8691 & 0.7553 & \\
\hline & fear3 & & & 0.6576 & 0.4324 & & & & 0.8783 & 0.7715 & \\
\hline \multirow{3}{*}{ Security } & secul & 0.4928 & 0.7470 & 0.9285 & 0.8620 & 0.4762 & 0.4645 & 0.7369 & 0.3015 & 0.0909 & 0.4141 \\
\hline & secu2 & & & 0.5486 & 0.3009 & & & & 0.5254 & 0.2760 & \\
\hline & secu3 & & & 0.5153 & 0.2655 & & & & 0.9356 & 0.8754 & \\
\hline \multirow{3}{*}{$\begin{array}{l}\text { Economic_ } \\
\text { conditions }\end{array}$} & ecosit1 & 0.6817 & 0.8263 & 0.7795 & 0.6076 & 0.5907 & 0.7596 & 0.8625 & 0.8339 & 0.6955 & 0.6679 \\
\hline & ecosit2 & & & 0.7078 & 0.5010 & & & & 0.7853 & 0.6167 & \\
\hline & ecosit3 & & & 0.8145 & 0.6634 & & & & 0.8316 & 0.6916 & \\
\hline \multicolumn{2}{|c|}{ Average communality } & & & & & 0.50 & & & & & 0.58 \\
\hline
\end{tabular}

Source: computations performed by the author using the XLSTAT-PLSPM software. 
Table 5. Inner model results for Ghana and Germany.

\begin{tabular}{ccccc}
\hline & \multicolumn{2}{c}{ Ghana } & \multicolumn{2}{c}{ Germany } \\
\hline Latent variables & Structural path & $\begin{array}{c}\text { Critical Ratio } \\
(\mathrm{CR})\end{array}$ & Structural path & $\begin{array}{c}\text { Critical Ratio } \\
(\mathrm{CR})\end{array}$ \\
\hline Social_capital & $0.1461^{* * *}$ & 23.2898 & $0.1535^{* * *}$ & 39.4575 \\
Religion & $0.0489^{* *}$ & 5.5680 & $0.0483^{* * *}$ & 11.2780 \\
Social_Trust & $0.0502^{* *}$ & 7.0987 & $0.1707^{* * *}$ & 33.7019 \\
Political_activities & -0.0500 & -10.6843 & $0.0467^{* * *}$ & 9.9482 \\
Personality & $0.0969^{* * *}$ & 16.9278 & $0.1006^{* * *}$ & 20.0946 \\
Fear & 0.0303 & -1.5929 & $0.0491^{* *}$ & 8.2290 \\
Security & $0.0559^{* * *}$ & 10.7902 & $0.0938^{* * *}$ & 19.7884 \\
Economic_conditions & $0.4109^{* * *}$ & 48.3407 & $0.2900^{* * *}$ & 64.5179 \\
$\mathrm{R}^{2}$ & 0.2436 & & 0.2533 & \\
Redundancy & $\mathbf{0 . 1 7 3 1}$ & & $\mathbf{0 . 2 0 3 5}$ &
\end{tabular}

Source: computations performed by the author using the XLSTAT-PLSPM software. ${ }^{*}$ significant at $10 \%$ if $\mathrm{CR}>2$; ${ }^{* *}$ significant at $5 \%$ if $\mathrm{CR}>5$; and ${ }^{* * *}$ significant at $1 \%$ if $\mathrm{CR}>10$.

The inner model shows that all variables or dimensions have a positive and significant effect on subjective well-being. The most important variables in determining subjective well-being among Germans are economic conditions; social trust and social capital (see Table 5).

\subsection{Invariance Measurement across Ghanaian and German Data}

The configural invariance is described in Table 6. Five constructed: social capital, religion, social trust, fear feeling or worries, and economic conditions are non-equivalent across two cultures. Thus, these dimensions are not comparable between Germany and Ghana and it is not relevant to compare their effects on subjective well-being between the two countries.

The results in Table 7 show that several indicators are non-invariant between the two groups. First, all items in the "religion" dimension are full non-invariant. worries of a terrorist attack (fear2) and worries of civil war (fear3) are two indicators of fear feeling dimension that are not equivalent between Germany and Ghana. The same is also true of political actions: "signing a petition" (actpo1) and making a "peaceful march" (actpo4) and the feeling of safety resulting from having a family member who has been the victim of a crime (secu2 and secu3). The importance of friends (socap2), trust in people one knows (trust3), and the feeling of belonging to a social class (ecosit2) were found to be non-equivalent between the two societies after all permutations $(n=100, n=500$ and $n=1000)$. Finally, well-being in the composition of the two indicators turns out to be non-equivalent only in terms of life satisfaction (swb1). The dimensions of political activity, security, and subjective well-being satisfy the criteria of configurative invariance. Given that some of their indicators do not meet the criterion of 
metric invariance, I can conclude for a partial invariance for these three dimensions. Thus, only the dimension relating to personality traits has full invariant measurement (the PLS-PM model does not allow for the measure of scale invariance).

In the inner model, Table 8 shows that the effect of social trust, political activities, fear feelings, and economic conditions prove to be non-equivalent. All these dimensions, except "policy actions", were found to be non-respect configural invariance measurement. Thus, Social capital and religion do not satisfy the criterion of configural invariance. As a result, they are non-invariant in both countries and it is not relevant to compare their effects on subjective well-being even if they are significantly different. This leaves only those personality traits and feelings of fear or dread that have effects on well-being that can be compared across the two countries. The personality traits that are invariant determine significantly subjective well-being across the two countries, but the effect is larger among Germans than Ghanaians. On the other hand, the sense of security that satisfies partial invariance has a much stronger effect on subjective well-being among Germans than among Ghanaians.

Table 6. Invariance testing for different dimensions.

\begin{tabular}{ccccc}
\hline \multirow{2}{*}{ Latent Variables } & $\mathrm{n}=30$ & $\mathrm{n}=100$ & $\mathrm{n}=1000$ & \multirow{2}{*}{ Significance } \\
\cline { 2 - 4 } & $P$ & $P$ & $P$ & \\
\hline Social_capital & 0.0968 & 0.0297 & 0.0060 & Yes \\
Religion & 0.0323 & 0.0099 & 0.0010 & Yes \\
Social_Trust & 0.0323 & 0.0099 & 0.0010 & Yes \\
Political_activities & 0.9032 & 0.9010 & 0.8991 & No \\
Personality & 1.0000 & 0.9505 & 0.9780 & No \\
Fear & 0.0323 & 0.0099 & 0.0010 & Yes \\
Security & 0.0645 & 0.1089 & 0.0989 & No \\
Economic_conditions & 0.0323 & 0.0099 & 0.0010 & Yes \\
Subjective well-being & 0.0579 & 0.0693 & 0.0645 & No
\end{tabular}

Source: computations performed by the author using the XLSTAT-PLSPM software.

Table 7. Invariance testing for different indicators.

\begin{tabular}{cccccc}
\hline \multirow{2}{*}{ Latent Variables } & Manifest variables & $\mathrm{n}=100$ & $\mathrm{n}=500$ & $\mathrm{n}=1000$ & \multirow{2}{*}{ Significance } \\
\cline { 3 - 5 } & socap1 & 0.0968 & 0.0990 & 0.0709 & No \\
\hline \multirow{2}{*}{ Social Capital } & socap2 & 0.0645 & 0.0594 & 0.0310 & Yes \\
& socap3 & 0.1290 & 0.0792 & 0.1249 & No \\
Religion & relig1 & 0.0323 & 0.0099 & 0.0010 & Yes \\
& relig2 & 0.0323 & 0.0099 & 0.0010 & Yes \\
& relig3 & 0.0323 & 0.0099 & 0.0010 & Yes \\
\hline
\end{tabular}


Continued

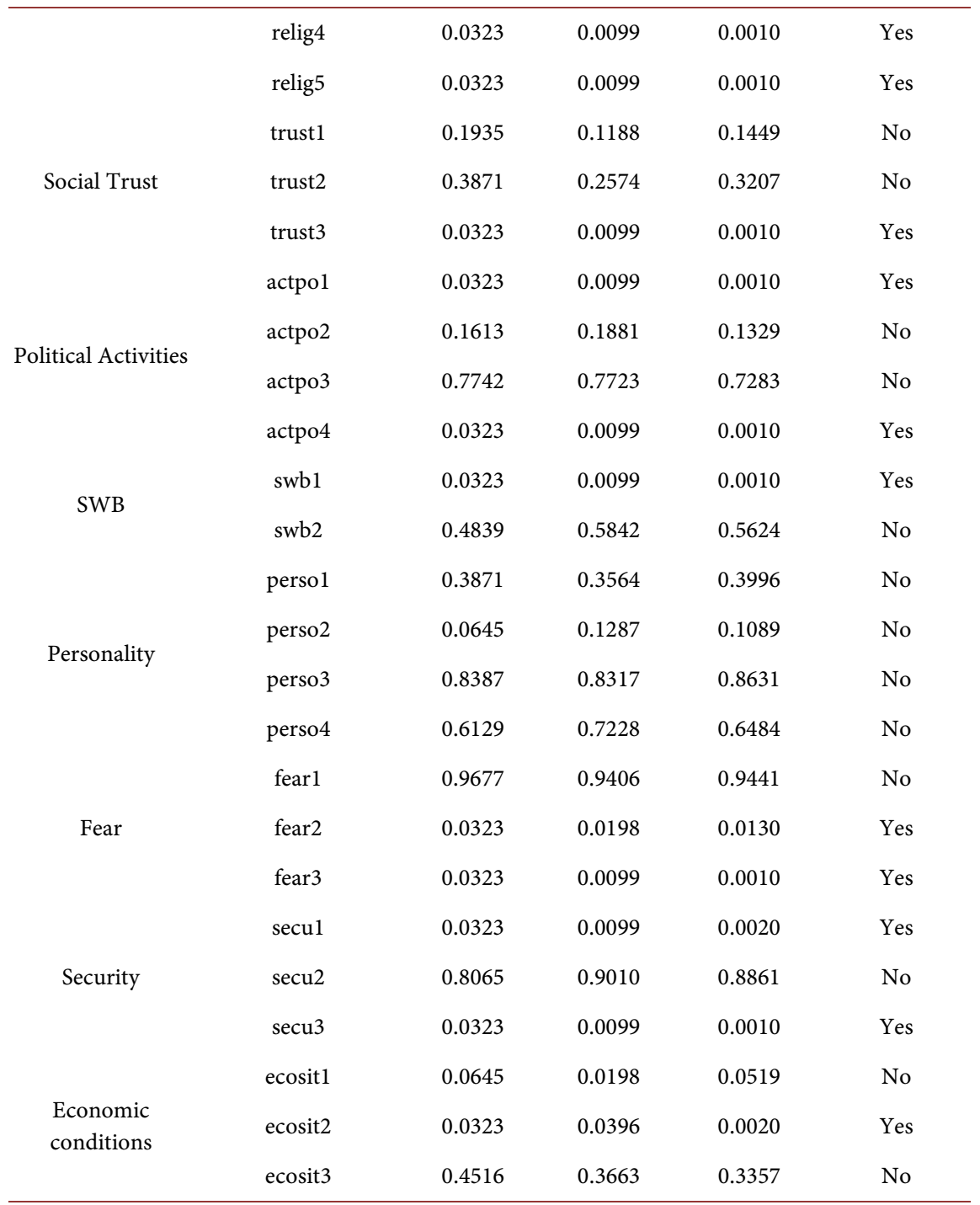

Source: computations performed by the author using the XLSTAT-PLSPM software.

Table 8. Structural paths invariance testing.

\begin{tabular}{ccccc}
\hline Latent Variables & $\mathrm{n}=100$ & $\mathrm{n}=500$ & $\mathrm{n}=1000$ & \multirow{2}{*}{ Significance } \\
\cline { 2 - 4 } & $P$ & $P$ & $P$ & No \\
Social_capital - > SWB & 0.8710 & 0.7822 & 0.7303 & No \\
Religion - $>$ SWB & 1.0000 & 0.9703 & 0.9590 & Yes \\
Social_Trust - $>$ SWB & $\mathbf{0 . 0 3 2 3}$ & $\mathbf{0 . 0 0 9 9}$ & $\mathbf{0 . 0 0 1 0}$ & Yes \\
Political_activities $->$ SWB & $\mathbf{0 . 0 3 2 3}$ & $\mathbf{0 . 0 0 9 9}$ & $\mathbf{0 . 0 0 1 0}$ & No \\
Personalities $->$ SWB & 0.8065 & 0.9406 & 0.8012 & Yes \\
Fear $->$ SWB & $\mathbf{0 . 0 3 2 3}$ & $\mathbf{0 . 0 0 9 9}$ & $\mathbf{0 . 0 0 1 0}$ & No \\
Security $->$ SWB & 0.3226 & 0.2079 & 0.0529 & Yes \\
Economic_conditions $->$ SWB & $\mathbf{0 . 0 3 2 3}$ & $\mathbf{0 . 0 0 9 9}$ & $\mathbf{0 . 0 0 1 0}$ &
\end{tabular}

Source: computations performed by the author using the XLSTAT-PLSPM software. 


\section{Conclusion}

The use of MGCFA to test the invariance of constructs between Germany and Ghana showed that there are concepts for which comparison between the two countries is impossible. These are social capital, religion, social trust, feelings of fear or dread, and economic conditions. The non-invariance of these dimensions between the two countries can be attributed to sociological as well as linguistic differences (Ghana is an English-speaking country). The objective of this paper is not to search for the source of non-invariance but just to show that it exists. However, it should be noted that apart from economic conditions, the other dimensions refer to values that appear in the WVS. In this sense, the non-invariance confirms to some extent the results of Davidov et al., (2011), and Sokolov, (2018) on the non-equivalence of most of the values measured in the WVS between countries with different cultural backgrounds such as those in Africa and Europe. The non-invariance of religion is one of the most striking between the two countries. This implies that religiosity, religious commitment, and faith issues are understood differently and that there is a different understanding of the opposition of a secularized society (Germany) to a traditional one (Ghana). The non-invariance of social capital and social trust between the two countries is more related, respectively, to the importance of friends in life and trust in neighbours. It may turn out that the notions of neighbours and friends are not the same in the two countries because of their cultural oppositions (Inglehart \& Welzel, 2005). The invariance of feelings of fear is linked to the fear of a terrorist attack and the fear of civil war. The geopolitical situation of the two countries is one reason for this difference. Germany, like many European countries, has been the victim of a terrorist attack in recent years, which is not the case in Ghana, even though it is a neighbour of Nigeria, which is under this type of threat. There could be a difference in the knowledge or experience of a danger such as a terrorist attack. The non-equivalence of economic conditions is related to the significant difference in the perception of belonging to a social class. This result suggests the importance of checking the invariance of economic situations before making a comparison of its effects on well-being between European and African countries.

Political activities, security, and subjective well-being have partial measure invariance, as they satisfy the configurative invariance but not the metric invariance. There are no studies in the literature that have tested the invariance of security and political activities. However, the welfare results are consistent with those of Bieda et al., (2017); Oishi, (2006), and Zanon et al., (2014) for the partial invariance observed in SWLS. Furthermore, the results on subjective well-being in this paper show that the item "life satisfaction" is non-invariant between Germany and Ghana. This result is different from those of Bieda et al., (2017); Jang et al., (2017); Jovanović \& Brdar, (2018) for whom the partial invariance of SWLS is more related to items 4 and 5 and not to item 3 (the one used in this paper). In Germany, the invariance of well-being is related to the item that is 
close to SHS (Bieda et al., 2017). Unlike this author, the results of this paper suggest an invariance of the perception of happiness between the two countries.

The personality traits associated with Scharwtz's values is the one dimension that is full invariant across the two countries. This result may to some extent confirm the idea that the five dimensions that form the personality traits defined by Schwartz are common to all cultures and societies (McCrae \& Terracciano, 2005). Moreover, this invariance can also be observed at the level of effects on subjective well-being, with a fairly small difference in favour of Germans. Besides, the sense of security for which there is partial measurement invariance has an effect on subjective well-being that is greater for Germans.

This study had an exploratory objective, and a future paper should focus on the analysis of invariance between a large number of African and European, Asian, or American countries to examine what is comparable in the measurement and determination of subjective well-being. Also, it would be more important in the future to compare tests of invariance using covariance-based SEMs (LISREL) and variance-based SEMs (PLSPM). The fact of not having integrated scale invariance is one of the limitations of this research and to remedy this, the LISREL method should be used with data that meet the criteria of normal distribution and heterogeneity among others.

\section{Conflicts of Interest}

The author declares no conflicts of interest regarding the publication of this paper.

\section{References}

Alemán, J., \& Woods, D. (2016). Value Orientations from the World Values Survey: How Comparable Are They Cross-Nationally? Comparative Political Studies, 49, 1039-1067. https://doi.org/10.1177/0010414015600458

Ariely, G., \& Davidov, E. (2011). Can We Rate Public Support for Democracy in a Comparable Way? Cross-National Equivalence of Democratic Attitudes in the World Value Survey. Social Indicators Research, 104, 271-286. https://doi.org/10.1007/s11205-010-9693-5

Bagozzi, R. P., Yi, Y., \& Nassen, K. D. (1998). Representation of Measurement Error in Marketing Variables: Review of Approaches and Extension to Three-Facet Designs. Journal of Econometrics, 89, 393-421. https://doi.org/10.1016/S0304-4076(98)00068-2

Barclay, D., Higgins, C., \& Thompson, R. (1995). The Partial Least Squares (PLS) Approach to Causal Modeling: Personal Computer Adoption and Use as an Illustration. Technology Studies, 2, 285-309.

Bieda, A., Hirschfeld, G., Schönfeld, P., Brailovskaia, J., Zhang, X. C., \& Margraf, J. (2017). Universal Happiness? Cross-Cultural Measurement Invariance of Scales Assessing Positive Mental Health. Psychological Assessment, 29, 408. https://doi.org/10.1037/pas0000353

Billiet, J. (2013). Quantitative Methods with Survey Data in Comparative Research. In $A$ Handbook of Comparative Social Policy (Second ed., p. 264). Cheltenham: Edward Elgar Publishing. https://doi.org/10.4337/9781782546535.00024 
Boeve-de Pauw, J., Jacobs, K., \& Van Petegem, P. (2014). Gender Differences in Environmental Values: An Issue of Measurement? Environment and Behavior, 46, 373-397. https://doi.org/10.1177/0013916512460761

Braun, M., \& Scott, J. (1998). Multidimensional Scaling and Equivalence: Is Having a Job the Same as Working? DEU.

Byrne, B. M. (2010). Structural Equation Modeling with AMOS Basic Concepts, Applications, and Programming (Multivariate Applications Series). New York: Routledge.

Byrne, B. M., Oakland, T., Leong, F. T., van de Vijver, F. J., Hambleton, R. K., Cheung, F. M., \& Bartram, D. (2009). A Critical Analysis of Cross-Cultural Research and Testing Practices: Implications for Improved Education and Training in Psychology. Training and Education in Professional Psychology, 3, 94. https://doi.org/10.1037/a0014516

Chen, F. F. (2008). What Happens If We Compare Chopsticks with Forks? The Impact of Making Inappropriate Comparisons in Cross-Cultural Research. Journal of Personality and Social Psychology, 95, 1005. https://doi.org/10.1037/a0013193

Chin, W. W. (1998). The Partial Least Squares Approach to Structural Equation Modeling. Modern Methods for Business Research, 295, 295-336.

Chin, W. W., \& Dibbern, J. (2010). An Introduction to a Permutation Based Procedure for Multi-Group PLS Analysis: Results of Tests of Differences on Simulated Data and a Cross Cultural Analysis of the Sourcing of Information System Services between Germany and the USA. In Handbook of Partial Least Squares (pp. 171-193). Berlin: Springer. https://doi.org/10.1007/978-3-540-32827-8_8

Chin, W. W., Mills, A. M., Steel, D. J., \& Schwarz, A. (2016). Multi-Group Invariance Testing: An Illustrative Comparison of PLS Permutation and Covariance-Based SEM Invariance Analysis. In H. Abdi, V. Esposito Vinzi, G. Russolillo, G. Saporta, \& L. Trinchera (Eds.), The Multiple Facets of Partial Least Squares and Related Methods (pp. 267-284). Berlin: Springer International Publishing.

https://doi.org/10.1007/978-3-319-40643-5_20

Churchill, S. A., \& Mishra, V. (2017). Trust, Social Networks and Subjective Wellbeing in China. Social Indicators Research, 132, 313-339.

https://doi.org/10.1007/s11205-015-1220-2

Davidov, E. (2009). Measurement Equivalence of Nationalism and Constructive Patriotism in the ISSP: 34 Countries in a Comparative Perspective. Political Analysis, 17, 64-82. https://doi.org/10.1093/pan/mpn014

Davidov, E., Datler, G., Schmidt, P., \& Schwartz, S. H. (2011). Testing the Invariance of Values in the Benelux Countries with the European Social Survey: Accounting for Ordinality. In Cross-Cultural Analysis: Methods and Applications (pp. 149-168). London/New York: Routledge.

Davidov, E., Meuleman, B., Cieciuch, J., Schmidt, P., \& Billiet, J. (2014). Measurement Equivalence in Cross-National Research. Annual Review of Sociology, 40, 55-75. https://doi.org/10.1146/annurev-soc-071913-043137

Diener, E. (1984). Subjective Well-Being. Psychological Bulletin, 95, 542-575. https://doi.org/10.1037/0033-2909.95.3.542

Diener, E. D., Emmons, R. A., Larsen, R. J., \& Griffin, S. (1985). The Satisfaction with Life Scale. Journal of Personality Assessment, 49, 71-75. https://doi.org/10.1207/s15327752jpa4901_13

Diener, E., Inglehart, R., \& Tay, L. (2013). Theory and Validity of Life Satisfaction Scales. Social Indicators Research, 112, 497-527. https://doi.org/10.1007/s11205-012-0076-y

Diener, E., Oishi, S., \& Lucas, R. E. (2003). Personality, Culture, and Subjective Well-Being: 
Emotional and Cognitive Evaluations of Life. Annual Review of Psychology, 54, 403-425. https://doi.org/10.1146/annurev.psych.54.101601.145056

Doll, W. J., Deng, X., Raghunathan, T. S., Torkzadeh, G., \& Xia, W. (2004). The Meaning and Measurement of User Satisfaction: A Multigroup Invariance Analysis of the End-User Computing Satisfaction Instrument. Journal of Management Information Systems, 21, 227-262. https://doi.org/10.1080/07421222.2004.11045789

Easterlin, R. (1974). Does Economic Growth Improve the Human Lot? Some Empirical Evidence. In Nations et Households in Economic Growth (pp. 89-125). Cambridge, MA: Academic Press. https://doi.org/10.1016/B978-0-12-205050-3.50008-7

Easterlin, R. A. (2001). Income and Happiness: Towards a Unified Theory. The Economic Journal, 111, 465-484. https://doi.org/10.1111/1468-0297.00646

Emerson, S. D., Guhn, M., \& Gadermann, A. M. (2017). Measurement Invariance of the Satisfaction with Life Scale: Reviewing Three Decades of Research. Quality of Life Research, 26, 2251-2264. https://doi.org/10.1007/s11136-017-1552-2

Fitzgerald, R., Widdop, S., Gray, M., \& Collins, D. (2011). Identifying Sources of Error in Cross-National Questionnaires: Application of an Error Source Typology to Cognitive Interview Data. Journal of Official Statistics, 27, 569-599.

Fornell, C., \& Larcker, D. F. (1981). Evaluating Structural Equation Models with Unobservable Variables and Measurement Error. Journal of Marketing Research, 18, 39-50. https://doi.org/10.1177/002224378101800104

Freitag, M., \& Bauer, P. C. (2013). Testing for Measurement Equivalence in Surveys: Dimensions of Social Trust across Cultural Contexts. Public Opinion Quarterly, 77, 24-44. https://doi.org/10.1093/poq/nfs064

Fydrich, T., Sommer, G., Tydecks, S., \& Brähler, E. (2009). Fragebogen zur sozialen unterstützung (F-SozU): Normierung der Kurzform (K-14). Zeitschrift Für Medizinische Psychologie, 18, 43-48.

Ha, S. E., \& Kim, S. (2013). Personality and Subjective Well-Being: Evidence from South Korea. Social Indicators Research, 111, 341-359.

https://doi.org/10.1007/s11205-012-0009-9

Harkness, J. A., Braun, M., Edwards, B., Johnson, T. P., Lyberg, L., Mohler, P. P., Pennell, B.-E., \& Smith, T. W. (2010). Wiley Series in Survey Methodology. In Survey Methods in Multinational, Multiregional, and Multicultural Contexts. Hoboken: John Wiley \& Sons, Inc. https://doi.org/10.1002/9780470609927.scard

Helliwell, J. F. (2005). Well Being, Social Capital and Public Policy: What's New? NBER Working Paper No. 11807, Cambridge, MA: National Bureau of Economic Research. https://doi.org/10.3386/w11807

Helliwell, J. F. (2008). Life Satisfaction and Quality of Development. Working Paper 14507, Cambridge, MA: National Bureau of Economic Research. https://doi.org/10.3386/w14507

Helliwell, J. F., \& Putnam, R. D. (2004). The Social Context of Well-Being. Philosophical Transaction of the Royal Society of London: Biological Sciences, 359, 1435-1446. https://doi.org/10.1098/rstb.2004.1522

Inglehart, R., \& Welzel, C. (2005). Modernization, Cultural Change, and Democracy: The Human Development Sequence. Cambridge: Cambridge University Press.

Jang, S., Kim, E. S., Cao, C., Allen, T. D., Cooper, C. L., Lapierre, L. M., O’Driscoll, M. P., Sanchez, J. I., Spector, P. E., \& Poelmans, S. A. (2017). Measurement Invariance of the Satisfaction with Life Scale across 26 Countries. Journal of Cross-Cultural Psychology, 48, 560-576. https://doi.org/10.1177/0022022117697844 
Johnson, T. P., \& Van de Vijver, F. J. (2003). Social Desirability in Cross-Cultural Research. Cross-Cultural Survey Methods, 325, 195-204.

Jöreskog, K. G. (1971). Simultaneous Factor Analysis in Several Populations. Psychometrika, 36, 409-426. https://doi.org/10.1007/BF02291366

Jovanović, V., \& Brdar, I. (2018). The Cross-National Measurement Invariance of the Satisfaction with Life Scale in a Sample of Undergraduate Students. Personality and Individual Differences, 128, 7-9. https://doi.org/10.1016/j.paid.2018.02.010

Kankaraš, M., Moors, G., \& Vermunt, J. K. (2010). Testing for Measurement Invariance with Latent Class Analysis. In Cross-Cultural Analysis: Methods and Applications (pp. 359-384). New York: Routledge.

Lim, C., \& Putnam, R. D. (2010). Religion, Social Networks, and Life Satisfaction. American Sociological Review, 75, 914-933. https://doi.org/10.1177/0003122410386686

Malhotra, M. K., \& Sharma, S. (2008). Measurement Equivalence Using Generalizability Theory: An Examination of Manufacturing Flexibility Dimensions. Decision Sciences, 39, 643-669. https://doi.org/10.1111/j.1540-5915.2008.00207.x

McCrae, R. R., \& Terracciano, A. (2005). Universal Features of Personality Traits from the Observer's Perspective: Data from 50 Cultures. Journal of Personality and Social Psychology, 88, 547. https://doi.org/10.1037/0022-3514.88.3.547

Meredith, W. (1964). Rotation to Achieve Factorial Invariance. Psychometrika, 29, 187-206. https://doi.org/10.1007/BF02289700

Nover, T. (2012). A Cross-Cultural Comparison of Mental Health Status in Adolescents. Trier: Universität Trier.

Oishi, S. (2006). The Concept of Life Satisfaction across Cultures: An IRT Analysis. Journal of Research in Personality, 40, 411-423. https://doi.org/10.1016/j.jrp.2005.02.002

Piurko, Y., Schwartz, S. H., \& Davidov, E. (2011). Basic Personal Values and the Meaning of Left-Right Political Orientations in 20 Countries. Political Psychology, 32, 537-561. https://doi.org/10.1111/j.1467-9221.2011.00828.x

Poznyak, D., Meuleman, B., Abts, K., \& Bishop, G. F. (2014). Trust in American Government: Longitudinal Measurement Equivalence in the ANES, 1964-2008. Social Indicators Research, 118, 741-758. https://doi.org/10.1007/s11205-013-0441-5

Raju, N. S., Laffitte, L. J., \& Byrne, B. M. (2002). Measurement Equivalence: A Comparison of Methods Based on Confirmatory Factor Analysis and Item Response Theory. Journal of Applied Psychology, 87, 517. https://doi.org/10.1037/0021-9010.87.3.517

Šarkute, L. (2017). Does Political Activism Induce Subjective Wellbeing: Evidence from ESS Data. International Journal of Psychology: A Biopsychosocial Approach, 21, 29-56. https://doi.org/10.7220/2345-024X.21.2

Sokolov, B. (2018). The Index of Emancipative Values: Measurement Model Misspecifications. American Political Science Review, 112, 395-408. https://doi.org/10.1017/S0003055417000624

Stanzani, S. (2015). Dimensions of Social Capital and Subjective Well-Being: Evidence from Italy. International Review of Sociology, 25, 129-143. https://doi.org/10.1080/03906701.2014.977586

Stevenson, B., \& Wolfers, J. (2013). Subjective Well-Being and Income: Is There Any Evidence of Satiation? The American Economic Review, 103, 598-604. https://doi.org/10.1257/aer.103.3.598

Stiglitz, J. E., Sen, A. K., \& Fitoussi, J.-P. (2009). Rapport de la Commission sur la mesure 
des performances économiques et du progrès social. http://www.ephygie.com/wp-content/uploads/2011/05/Rapport-de-la-Commission-sur -la-mesure-des-performances-\%C3\%A9conomiques-et-du-progr\%C3\%A8s-social-Rap port-Stiglitz.pdf

Tenenhaus, M., Vinzi, V. E., Chatelin, Y.-M., \& Lauro, C. (2005). PLS Path Modeling. Computational Statistics \& Data Analysis, 48, 159-205. https://doi.org/10.1016/j.csda.2004.03.005

Tian, L., Zheng, J., Huebner, E. S., \& Liu, W. (2020). Brief Adolescents' Subjective Well-Being in School Scale: Measurement Invariance and Latent Mean Differences across School Levels among Chinese Students. Current Psychology, 1-9. https://doi.org/10.1007/s12144-020-00841-x

Tomás, J. M., Gutiérrez, M., Sancho, P., \& Romero, I. (2015). Measurement Invariance of the Satisfaction with Life Scale (SWLS) by Gender and Age in Angola. Personality and Individual Differences, 85, 182-186. https://doi.org/10.1016/j.paid.2015.05.008

Triandis, H. C. (1972). The Analysis of Subjective Culture. Wiley Online Library.

Tsai, J. L., Miao, F. F., \& Seppala, E. (2007). Good Feelings in Christianity and Buddhism: Religious Differences in Ideal Affect. Personality and Social Psychology Bulletin, 33, 409-421. https://doi.org/10.1177/0146167206296107

Tucker, K. L., Ozer, D. J., Lyubomirsky, S., \& Boehm, J. K. (2006). Testing for Measurement Invariance in the Satisfaction with Life Scale: A Comparison of Russians and North Americans. Social Indicators Research, 78, 341-360. https://doi.org/10.1007/s11205-005-1037-5

Van de Vijver, F. J. (1998). Towards a Theory of Bias and Equivalence. DEU.

Veenhoven, R. (2010). Capability and Happiness: Conceptual Difference and Reality Links. The Journal of Socio-Economics, 39, 344-350.

https://doi.org/10.1016/j.socec.2009.11.007

Vinzi, E. V., \& Russolillo, G. (2010). Partial Least Squares Path Modeling and Regression. Wiley Interdisciplinary Reviews: Computational Statistics, 5, 1-19. https://doi.org/10.1007/978-3-540-32827-8

Welzel, C. (2013). Freedom Rising. Cambridge: Cambridge University Press. https://doi.org/10.1017/CBO9781139540919

Wetzels, M., Odekerken-Schröder, G., \& Van Oppen, C. (2009). Using PLS Path Modeling for Assessing Hierarchical Construct Models: Guidelines and Empirical Illustration. MIS Quarterly, 33, 177-195. https://doi.org/10.2307/20650284

Wierzbicka, A. (2004). "Happiness" in Cross-Linguistic \& Cross-Cultural Perspective. Daedalus, 133, 34-43. https://doi.org/10.1162/001152604323049370

Willis, G. B. (2004). Cognitive Interviewing: A Tool for Improving Questionnaire Design. Thousand Oaks, CA: Sage Publications.

Zanon, C., Bardagi, M. P., Layous, K., \& Hutz, C. S. (2014). Validation of the Satisfaction with Life Scale to Brazilians: Evidences of Measurement Noninvariance across Brazil and US. Social Indicators Research, 119, 443-453.

https://doi.org/10.1007/s11205-013-0478-5

Żemojtel-Piotrowska, M., Piotrowski, J. P., Cieciuch, J., Adams, B. G., Osin, E. N., Ardi, R., Bălțătescu, S., Bhomi, A. L., Clinton, A., \& De Clunie, G. T. (2017). Measurement Invariance of Personal Well-Being Index (PWI-8) across 26 Countries. Journal of Happiness Studies, 18, 1697-1711. https://doi.org/10.1007/s10902-016-9795-0 


\section{Appendix}

Table A1. Dimensions, indicators, and scales.

\begin{tabular}{|c|c|c|c|c|}
\hline Dimension & Indicator & Definition in WVS & Scale & \\
\hline \multirow{3}{*}{$\begin{array}{l}\text { Social } \\
\text { Capital }\end{array}$} & Socap1 & $\begin{array}{l}\text { Active/Inactive membership: Sport or recreational } \\
\text { organization }\end{array}$ & \multicolumn{2}{|l|}{$\begin{array}{l}\text { 1) Not a member } \\
\text { 2) Inactive member } \\
\text { 3) Active member }\end{array}$} \\
\hline & Socap2 & Important in life: friends & 1) Not all important & 3) Rather important \\
\hline & Socap3 & Important in life: times leasures & 2) Not very important & 4) Very Important \\
\hline \multirow{5}{*}{ Religions } & Rel1 & How often to pray & $\begin{array}{l}\text { Never, practically never } \\
\text { Less often than once a year } \\
\text { One year } \\
\text { Only on special holy day }\end{array}$ & $\begin{array}{l}\text { Only when attending } \\
\text { religious services } \\
\text { Several times each week } \\
\text { Once a day } \\
\text { Several time a day }\end{array}$ \\
\hline & Rel2 & How often do you attend religious services & $\begin{array}{l}\text { Never, practically never } \\
\text { Less often } \\
\text { Once a year } \\
\text { Only on special holy day }\end{array}$ & $\begin{array}{l}\text { Once a month } \\
\text { Once a week } \\
\text { More than once a week }\end{array}$ \\
\hline & Rel3 & Important in life: religion & $\begin{array}{l}\text { 1) Not all important } \\
\text { 2) Not very important } \\
\text { 3) Rather important } \\
\text { 4) Very Important }\end{array}$ & \\
\hline & Rel4 & How important is God in your life & $\begin{array}{l}\text { Not at all important } \\
\ldots\end{array}$ & $\begin{array}{l}\cdots \\
\text { Very important }\end{array}$ \\
\hline & Rel5 & $\begin{array}{l}\text { Active/Inactive membership: Church or Religious } \\
\text { organization }\end{array}$ & $\begin{array}{l}\text { 1) Not a member } \\
\text { 2) Inactive member } \\
\text { 3) Active member }\end{array}$ & \\
\hline \multirow{4}{*}{ Social Trust } & Trust1 & How much you trust: Your family & Do not trust at all & \\
\hline & Trust2 & How much you trust: Your neighborhood & $\begin{array}{l}\text { Do not trust very much } \\
\text { Trust somewhat }\end{array}$ & \\
\hline & Trust3 & How much you trust: people you know personally & Trust completely & \\
\hline & Persol & $\begin{array}{l}\text { Schwartz: It is important to this person to think up } \\
\text { new ideas and be creative; }\end{array}$ & Not at all like me & \\
\hline \multirow{3}{*}{ Personality } & Perso2 & $\begin{array}{l}\text { Schwartz: It is important to this person to be rich; } \\
\text { to have a lot of money and }\end{array}$ & $\begin{array}{l}\text { Not like me } \\
\text { A little like me }\end{array}$ & \\
\hline & Perso3 & $\begin{array}{l}\text { Schwartz: Adventure and taking risks are important } \\
\text { to this person; to have an ex }\end{array}$ & $\begin{array}{l}\text { Somewhat like me } \\
\text { Like me }\end{array}$ & \\
\hline & Perso4 & $\begin{array}{l}\text { Schwartz: Being very successful is important to this person; } \\
\text { to have people recognition }\end{array}$ & Very much like me & \\
\hline \multirow{4}{*}{$\begin{array}{l}\text { Political } \\
\text { Activities }\end{array}$} & Actpo1 & Political action: Signing a petition & & \\
\hline & Actpo2 & Political action: Joining boycotts & Would never do & \\
\hline & Actpo3 & Political action: Joining stricks & Have done & \\
\hline & Actpo4 & Political action: attending peaceful demonstration & & \\
\hline \multirow{3}{*}{ Fear } & Fearl & Worries: A war involving my country & Very much & \\
\hline & Fear2 & Worries: A terrorist attack & $\begin{array}{l}\text { A great deal } \\
\text { Not much }\end{array}$ & \\
\hline & Fear3 & Worries: A civil war & Not at all & \\
\hline \multirow{3}{*}{ Security } & Secul & Respondent was victim of a crime during the past year & Yes & \\
\hline & Secu2 & Respondent's family was victim of a crime during last year & No & \\
\hline & Secu3 & $\begin{array}{l}\text { In the last } 12 \text { month, how often have you or your family: } \\
\text { Felt unsafe from crime }\end{array}$ & $\begin{array}{l}\text { Often } \\
\text { Sometimes }\end{array}$ & $\begin{array}{l}\text { Rarely } \\
\text { Never }\end{array}$ \\
\hline
\end{tabular}


Continued

\begin{tabular}{|c|c|c|c|c|}
\hline \multirow{3}{*}{$\begin{array}{l}\text { Economic } \\
\text { conditions }\end{array}$} & Ecosit1 & Scale of incomes & $\begin{array}{l}\text { Lower step } \\
\text { Second step }\end{array}$ & $\begin{array}{l}\cdots \\
\ldots \\
10) \text { Tenth step }\end{array}$ \\
\hline & Ecosit2 & Social class (subjective) & $\begin{array}{l}\text { 1) Lower class } \\
\text { 2) Working-class } \\
\text { 3) Lower middle class }\end{array}$ & $\begin{array}{l}\text { 4) Upper middle class } \\
\text { 5) Upper class }\end{array}$ \\
\hline & Ecosit3 & Satisfaction with financial situation & 1) Completely dissatisfied & 9) $\ldots$ \\
\hline Subjective & Swb1 & Satisfaction with your life & 2) $\ldots$ & 10) Completely satisfied \\
\hline wellbeing & Swb2 & Feeling of happiness & $\begin{array}{l}\text { 1) Not All Happy } \\
\text { 2) Not Very Happy }\end{array}$ & $\begin{array}{l}\text { 3) Rather Happy } \\
\text { 4) Very Happy }\end{array}$ \\
\hline
\end{tabular}

Source: Author.

Table A2. WVS data descriptive statistics.

\begin{tabular}{|c|c|c|c|c|c|c|c|}
\hline Variable & Observations & Ghana & Germany & Minimum & Maximum & Means & Standard deviation \\
\hline socap1 & 3030 & 1501 & 1529 & 0.0000 & 2.0000 & 0.5663 & 0.8270 \\
\hline socap2 & 3030 & 1501 & 1529 & 1.0000 & 4.0000 & 3.3399 & 0.7534 \\
\hline socap3 & 3030 & 1501 & 1529 & 1.0000 & 4.0000 & 3.3043 & 0.7049 \\
\hline relig1 & 3030 & 1501 & 1529 & 1.0000 & 8.0000 & 5.1191 & 2.9067 \\
\hline relig2 & 3030 & 1501 & 1529 & 1.0000 & 7.0000 & 4.1617 & 2.3753 \\
\hline relig3 & 3030 & 1501 & 1529 & 1.0000 & 4.0000 & 2.9561 & 1.2052 \\
\hline relig4 & 3030 & 1501 & 1529 & 1.0000 & 10.0000 & 7.0086 & 3.5948 \\
\hline relig5 & 3030 & 1501 & 1529 & 0.0000 & 2.0000 & 1.0799 & 0.8553 \\
\hline trust1 & 3030 & 1501 & 1529 & 1.0000 & 4.0000 & 3.6248 & 0.6774 \\
\hline trust2 & 3030 & 1501 & 1529 & 1.0000 & 4.0000 & 2.6911 & 0.7908 \\
\hline trust3 & 3030 & 1501 & 1529 & 1.0000 & 4.0000 & 2.8726 & 0.7510 \\
\hline actpo1 & 3030 & 1501 & 1529 & 1.0000 & 3.0000 & 1.8125 & 0.8248 \\
\hline actpo2 & 3030 & 1501 & 1529 & 1.0000 & 3.0000 & 1.4092 & 0.6108 \\
\hline actpo3 & 3030 & 1501 & 1529 & 1.0000 & 3.0000 & 1.5228 & 0.6345 \\
\hline actpo4 & 3030 & 1501 & 1529 & 1.0000 & 3.0000 & 1.7208 & 0.7202 \\
\hline swb1 & 3030 & 1501 & 1529 & 1.0000 & 10.0000 & 6.9667 & 2.1776 \\
\hline swb2 & 3030 & 1501 & 1529 & 1.0000 & 4.0000 & 3.2254 & 0.7440 \\
\hline perso 1 & 3030 & 1501 & 1529 & 1.0000 & 6.0000 & 4.6056 & 1.1807 \\
\hline perso2 & 3030 & 1501 & 1529 & 1.0000 & 6.0000 & 3.8515 & 1.5465 \\
\hline perso3 & 3030 & 1501 & 1529 & 1.0000 & 6.0000 & 3.4776 & 1.6231 \\
\hline perso 4 & 3030 & 1501 & 1529 & 1.0000 & 6.0000 & 4.6835 & 1.1826 \\
\hline fearl & 3030 & 1501 & 1529 & 1.0000 & 4.0000 & 2.2020 & 1.1833 \\
\hline fear2 & 3030 & 1501 & 1529 & 1.0000 & 4.0000 & 2.1518 & 1.1181 \\
\hline fear3 & 3030 & 1501 & 1529 & 1.0000 & 4.0000 & 2.4611 & 1.3139 \\
\hline secul & 3030 & 1501 & 1529 & 1.0000 & 5.0000 & 4.7439 & 0.9792 \\
\hline secu2 & 3030 & 1501 & 1529 & 1.0000 & 5.0000 & 4.6871 & 1.0741 \\
\hline secu3 & 3030 & 1501 & 1529 & 1.0000 & 4.0000 & 3.6894 & 0.6532 \\
\hline ecosit1 & 3030 & 1501 & 1529 & 1.0000 & 10.0000 & 4.8822 & 1.9318 \\
\hline ecosit2 & 3030 & 1501 & 1529 & 1.0000 & 5.0000 & 2.7403 & 1.0037 \\
\hline ecosit3 & 3030 & 1501 & 1529 & 1.0000 & 10.0000 & 5.7752 & 2.5784 \\
\hline
\end{tabular}

Source: Author, from WVS data. 